\title{
Systematic Introduction of Vocabulary and its Effect on Acquisition: Primary Education Students of English as a Foreign Language
}

\author{
Gema Alcaraz MÁrmol \\ Universidad Católica de San Antonio
}

Received: 1 November 2011 / Accepted: 17 February 2012

ISSN: $1697-7467$

\begin{abstract}
The aim of the present study is to find out whether there exists a relation between word distribution and receptive and productive acquisition. A group of 20 students of EFL took two vocabulary tests based on L1-L2 and L2-L1 translation. The test items were target words from the students' coursebook. These words had been previously attributed an index of dispersion (Gries 2008). Results show that those words which were more regularly distributed had a higher level of acquisition. In the light of these results, a regular and systematic introduction is recommended for vocabulary acquisition within the context of Foreign Language Learning.
\end{abstract}

Keywords: Foreign Language, regular distribution, language teaching, vocabulary acquisition.

La introducción sistemática del vocabulario y su efecto en la adquisición: estudiantes de educación primaria de inglés como lengua extranjera

RESUMEN: El presente estudio tiene como objetivo averiguar si existe una relación entre la distribución de una palabra en un texto y su adquisición receptiva y productiva. Un total de 20 estudiantes de inglés como LE realizaron dos tests de vocabulario consistentes en traducción inversa y directa de palabras clave del libro de texto que seguían. Previamente, a cada una de las palabras se les había calculado un índice de dispersión (Gries 2008). Los resultados muestran que aquellas palabras cuya distribución era más regular presentaban un grado de adquisición mayor. Por tanto, se recomienda una introducción sistemática del vocabulario para su aprendizaje dentro de un contexto de lengua extranjera.

Palabras clave: Distribución regular, enseñanza de lenguas, lengua extranjera, adquisición léxica.

\section{INTRODUCTION}

Nowadays it is beyond doubt that vocabulary is one of the cornerstones in Foreign Language learning. It is estimated that a learner needs to know at least 2000 words in order to be able to communicate. Yet Schmitt warns that "this will not enable a conversation on every topic, and certainly not an in-depth conversation on most topics" (Schmitt, 2000:142). Admittedly, we have to be realistic and recognize that this amount limits the speaker in some respects. However, despite limitations, the author goes on to say that 
the 2000 most frequent word families "should still allow satisfying interactions with native speakers on topics focusing on everyday events and activities" (ibid). Nation (2001) adds that this figure normally represents $84 \%$ of a general, non-specialized text. By contrast, Laufer (1995) is more optimistic and increases this percentage up to $95 \%$.

Unfortunately, several studies reveal that learners do not usually seem to reach this threshold level. For instance, Quinn (1968) discovered that university students had a very low L2 vocabulary level despite having studied it for several years. On average, students had only managed to acquire 1000 words after seven years of instruction. The results uncovered by Jiménez Catalán and Terrazas (2008) and Jiménez Catalán and Moreno Espinosa (2005) did not fare much better. These two studies showed that Elementary school children were really far from expectations in their vocabulary acquisition. Secondary school students, for their part, did not perform much better either. On average, they did not even reach 1000 words after ten years of instruction.

Experts on L2 acquisition have tried to find a solution to improve these low numbers. Some of them point to frequency. We can distinguish between general and specific frequency. The former refers to occurrences in general discourse, whereas the latter corresponds to word occurrences in a given text. In this sense, it is not unusual to find words with a high specific frequency in a textbook, for instance, yet a low frequency in general discourse, and vice versa. This is common when a second language is learned for a specific purpose, for example Medicine or Law. General frequency has proven to be a determining factor in L2 vocabulary acquisition (Brown 1993). Based on general frequency, Meara (1992) designed a model of frequency profile which seemed to be accurate in the way it characterized vocabulary growth in groups of learners. According to this model, learners are sensitive to the general frequency of occurrence of the words they encounter. Logically enough, words with higher frequency are expected to occur more often in discourse, providing learners with more chances to acquire them.

Yet, a large part of the L2 community learns vocabulary in a non-naturalistic environment, where the second language becomes a foreign language, not an L2. These formal contexts limit exposure almost exclusively to the classroom. The classroom is a microcosm where most learning processes develop. Consequently, the learners' vocabulary acquisition will mainly depend on the input provided by the teacher and the textbook, which may or may not coincide with the frequency levels of general discourse in that language.

Therefore, from the standpoint of a foreign language context, I consider specific frequency to be of greater interest than general frequency, given the pedagogical applications it may offer. To date, there is no agreement on the number of occurrences that are necessary for acquisition. What is more, we do not even know whether all words need to be encountered the same number of times. A number of studies have focused on this issue. Scholars have tried to determine, as accurately as possible, the number of times a word needs to occur to enable acquisition. What we find in this respect are various different outcomes, ranging from 5 to 20 occurrences.

Scholars such as Kachroo (1962), Horst et al. (1998) and Rott (1999) suggest that a word needs to appear at least 6 to 8 times for the learner to have a real chance of acquiring it. Rott (1999) compared three groups of learners with different amounts of exposure to the same words. Words occurred 2, 4 and 6 times. The group with the highest exposure was the one which experienced a higher degree of acquisition. Kachroo (1962) 
observed that most learners acquired words occurring no less than 7 times. In the same line, Horst et al. found that no significant gains were possible for a word which occurred less than 8 times.

For other scholars the minimum number of occurrences for significant acquisition must be placed at 9 to 10 times. For Saragi et al. (1978), Reyes (1999) and Webb (2007) impact on vocabulary acquisition can only be observed when the word appears over 9 times. Some authors (Waring and Takaki 2003; Pigada and Schmitt 2006) go even further by suggesting that it takes at least 20 occurrences for a word to become noticeable to a learner. In the light of these results, it appears that 2 or 3 encounters with a word imply no gaining of knowledge. It may be the case that encountering a word once or twice may not be enough for discerning its meaning or recalling its form, but it can trigger some degree of recognition (Hulstijn et al. 1996). Nagy and Herman claim that "even a single encounter with a word in context [might push it up] a little big higher on the scale of knowledge" (Nagy and Herman, 1987:25).

Nonetheless, and despite the relevant advances regarding specific frequency in L2 vocabulary acquisition, this factor may sometimes be a misleading indicator of the overall importance of a word (Gries 2008; Leech et al. 2001). In fact, frequency of occurrence can run into problems when the distribution of elements is not taken into consideration. Gries (2008) holds that distribution is highly relevant as a factor for both acquisition and corpus linguistics statistics. The author also states that the number of occurrences plays a role, and they should be related to distribution, so that we should talk about dispersion. Range, the maximum-minimum difference, the standard deviation, the variation coefficient, the chi-squared, or those proposed by Lyne (1985) or Zhang et al. (2004) are some of those indices. Yet, there are two main problems with all these measures: either they are not specifically geared to the dispersion of linguistic items in texts or, if they are, they are too complicated to calculate.

As an alternative to these indices of dispersion, Gries suggests what he calls the deviation of proportions (DP). According to the author, the DP is "conceptually simpler and more versatile than many competing measures" (Gries, 2008:197). This measure allows us to quantify the dispersion of lexical items, and does not rely on the unwarranted assumption of equally-sized corpus parts.

\section{Aim}

With these premises in mind, our aim is to find out whether Gries' DP has an effect on L2 vocabulary acquisition, and whether this effect is different in receptive and productive knowledge.

\section{Methodology}

\subsection{Participants}

The group of participants for this study consists of 20 students of English in their third year of Primary Education. At the moment the study was carried out, the students 
had received around 186 hours of instruction, equating to an Elementary level of English. They all belonged to the same public school in the Region of Murcia and spoke Spanish as their mother tongue.

\subsection{Materials: Words and Vocabulary tests}

The object of study is a group of 30 English words. They appeared in Bugs 3 (Macmillan), the coursebook which participants followed during the lessons. This coursebook is based on the Communicative Method and it is well-known among students, teachers and parents. Words have been chosen from among all target words in the textbook, avoiding cognates such as tennis, competition or delicious. The coursebook was the guide that the teacher used for the lesson and it was accurately followed.

Gries' index of dispersion (Deviation of Proportions) was calculated for each target word according to its disposition in the coursebook. To determine the DP of the words three steps were taken. The first step consists of determining the sizes of each of the corpus parts. These are normalized against the overall corpus size and correspond to expected percentages which take differently-sized corpus parts into consideration. In the second place, we need to determine the frequency with which the words occur in the corpus parts. They are normalized against the overall number of word occurrences and correspond to an observed percentage. Finally, we need to compute all pairwise absolute differences of observed and expected percentages, add them up, and divide the result by two. The results of these steps give a number which is the word DP index. The closer this number is to zero, the more regular the dispersion of the word in the text is (see table 1).

At the end of the course the 20 participants took two tests. The first one consisted of an L1-L2 translation test where students had to find the L2 term for each of the 30 words. In the second test students had to find the L1 equivalent for L2 forms. In both tests words were organized alphabetically. The productive test was taken first. Students had 30 minutes to complete it. After this first test a distractive activity of three minutes was carried out. After this short activity the second test was distributed.

A dual system was used for test scoring. Accordingly, items scored 0 when no answer or wrong answer was provided in the L2-L1 translation test. Possible errors of spelling in the L1 answers ( $\mathrm{b} / \mathrm{v}$ confusion such as baso instead of vaso or absence of $\mathrm{h}$ such as ablar instead of hablar) were not taken into consideration as the aim was to find out whether the students recognized the L2 form and knew its meaning. In the case of the L1-L2 translation test minor spelling errors were not taken into consideration unless they distorted the meaning of the word, or the word form itself was not understandable. The first condition can be illustrated by the following example: the use of grass instead of glass for the translation of vaso. The two words exist in English, but the spelling error of using ' $r$ ' instead of ' 1 ' transforms the word into a totally different term with a completely different meaning. The second condition holds if the student writes lagss instead of glass. 
Table 1. Target words and their DPs

\begin{tabular}{|l|l|l|l|l|l|}
\hline Word & DP & Word & DP & Word & DP \\
\hline Bad & 0.9 & Egg & 3.27 & Party & 1.81 \\
\hline Bed & 2.27 & Finger & 0.9 & Rice & 3.63 \\
\hline Bike & 1.81 & Fly & 1.63 & Score & 5.45 \\
\hline Bread & 0.9 & Fork & 2.27 & Shoot & 0.9 \\
\hline Breakfast & 7.27 & Garden & 0.9 & Soap & 0.9 \\
\hline Brush & 7.36 & Glass & 0.9 & Spoon & 0.9 \\
\hline Butterfly & 0.9 & Great & 4.09 & Swim & 5.27 \\
\hline Canteen & 0.9 & Juice & 2.45 & Throw & 4.54 \\
\hline Cheese & 0.9 & Knife & 3.63 & Turn & 2.45 \\
\hline Children & 2.27 & Lunch & 4.09 & Win & 0.9 \\
\hline
\end{tabular}

In order to find out whether the DP had an effect on vocabulary acquisition two univariate regressions were carried out, one for each type of test. The independent variable for the analysis corresponds to the number of acquisitions registered in each word, whereas the dependent variable indicates the words' index of dispersion.

\subsection{Data analysis}

The program SPSS (version 15.0) was used for the data analysis. Two different univariate regressions were carried out, one for receptive knowledge and one for productive knowledge. The independent variable in these regressions corresponds to the word index of dispersion (DP), whereas the dependent variable indicates the number of acquisitions registered for each word.

\section{Results AND DISCUSSION}

The regression analyses show that Gries' DP has an effect on word acquisition. Put another way, words with low DPs, that is, those words which are more regularly distributed, are more acquired, that is to say, more words are acquired if there is a systematic introduction. by learners than those with a more irregular distribution. Statistical data reveal that this relation is highly significant both for receptive and productive knowledge, especially for the former. The significant effect of the DP on productive knowledge is .002 (F11.459), while significance reaches .000 (F65.206) in receptive knowledge (see tables 2 and 3$)$.

These results support the suggestions by some authors about a systematic introduction of vocabulary in Foreign Language teaching contexts. Their idea of vocabulary teaching 
is based on the introduction of a specific number of words at certain moments in time. Yet, these ideas are far from the reality of the classroom. Scholars such as Milton (2009) or Scholfield (1991) warn about the "unstable lexical economy" (Scholfield 1991: 1) in vocabulary teaching. This expression reflects the situation of vocabulary teaching in the Foreign Language classroom. In his analysis of different courses Scholfield used a vocabulary rate plot to know the rate at which vocabulary was introduced. The coursebook is normally the guide for teachers. It is considered a very important tool - some would say the tool - in the classroom. In fact, Yuen (1997) calls the coursebook an inevitable teaching partner from which teachers cannot ask for a divorce (Yuen 1997).

Table 2. Univariate linear regression for receptive knowledge

\begin{tabular}{|l|l|c|c|}
\hline \multicolumn{2}{|l|}{ Model } & F & Sig. \\
\hline \multirow{2}{*}{} & (Constant) & &, 000 \\
& & 65,206 & \\
\cline { 2 - 4 } & INDEX & &, 000 \\
\hline
\end{tabular}

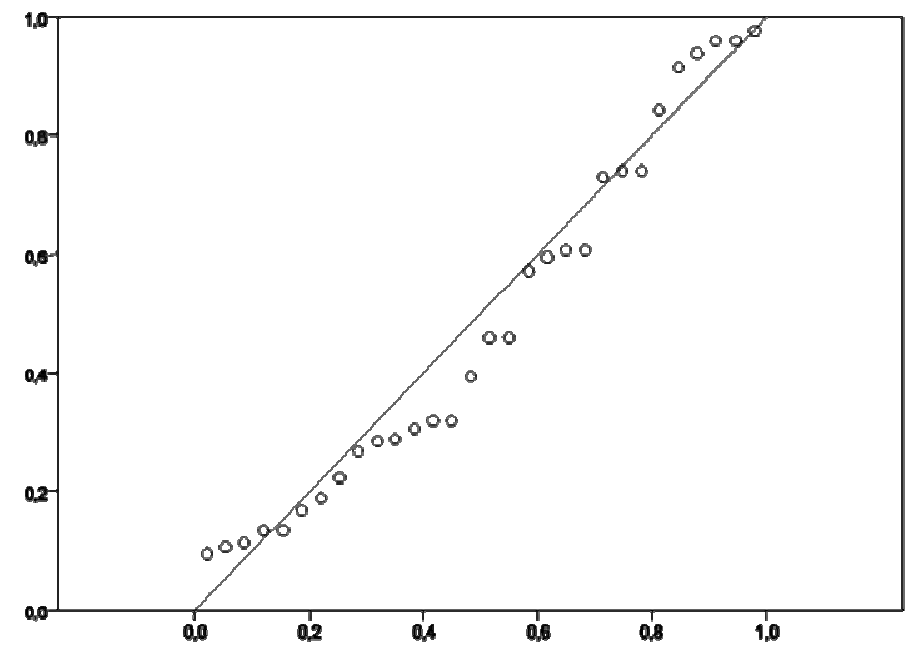

Figure 1. DP index and Receptive knowledge

Despite scholars' claim for systematic vocabulary introduction, coursebooks still present vocabulary in a way which is clearly far from any systematic basis. Irregularity is not only found intra-coursebooks but also inter-coursebooks. In other words, we can find coursebooks targeting the same learner's profile which present important differences regarding the quantity and quality of their target vocabulary. In his coursebook analyses 
Scholfield found "considerable differences between courses [...] and a great deal of variation between one unit and another" (Scholfield, 1991:12). The range of vocabulary varied from 21 to 58 items.

A more recent study by Alcaraz-Mármol (in press) specifically focuses on two popular EFL coursebooks in Spain. She highlights the different philosophy behind the way vocabulary is treated. Even though both textbooks target the same audience, the number and type of words differ considerably from one textbook to the other. What is even more interesting, their distribution patterns are not in the same line. In the first place, both offer irregular introduction of new input. However, whereas one of them shows an increasing tendency, the other one introduces less and less vocabulary as didactic units develop.

Table 3. Univariate linear regression for productive knowledge

\begin{tabular}{|l|l|c|c|}
\hline \multicolumn{2}{|l|}{ Model } & F & Sig. \\
\hline \multirow{2}{*}{} & (Constant) & &, 000 \\
& & 11,459 &, 002 \\
\cline { 2 - 5 } & INDEX & & \\
\hline
\end{tabular}

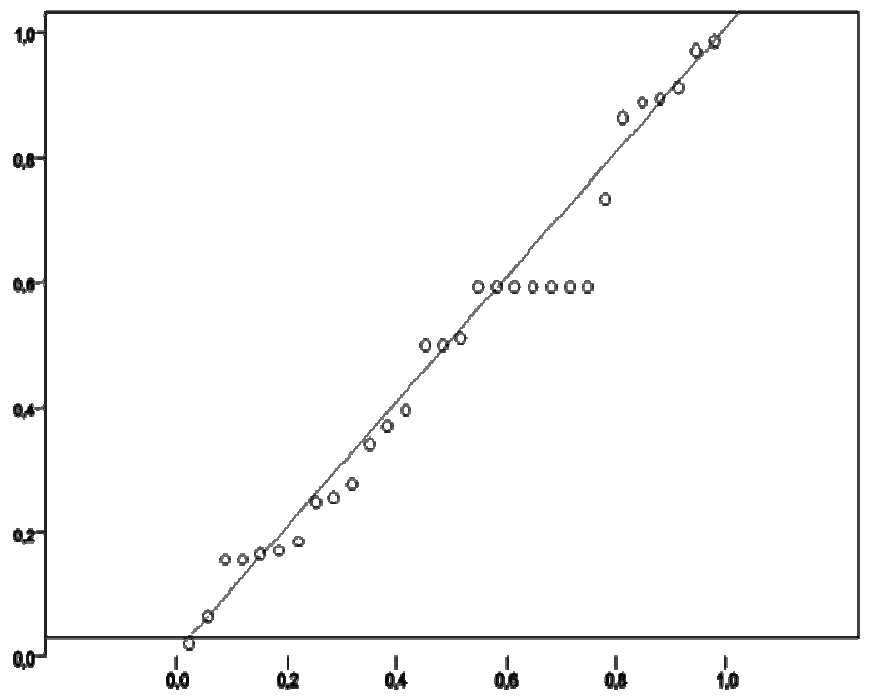

Figure 2. DP index and productive knowledge

By contrast, we also find studies where vocabulary introduction is systematic, and where the levels of vocabulary acquisition are high. Milton states that "successful language teaching environments are characterized by regular vocabulary uptake in classes 
of learners" (Milton, 2009:68). In his observation of the Greek system he describes vocabulary learning as a "very regular business" (Milton, 2009:68). He observed that most learners showed good and regular progress in their vocabulary development. Another example of regular introduction is presented by Orosz (2009). His study about the Hungarian state school system seems to be in line with Greece. Both authors remark on the learners' foreign language success in these systems, which is in part attributed to the regular pattern of vocabulary introduction adopted. In contrast with these two systems, Milton comments on British learners of French as an FL in schools. He warns about the little noticeable progress in vocabulary knowledge among students. They make a good start in their vocabulary knowledge, but after some time their rate of acquisition starts decreasing. This can be expected at some point, because as vocabulary level increases acquisition decreases. However, this decrease should not be so marked and start so early. In fact, this decrease also happens after some years of instruction in the Greek and Hungarian systems, qualified as "rather good" (Miton, 2009:70). The difference is that learners here end up with a good level of vocabulary, while students of French in Britain do not.

As regular introduction has proved to be related to acquisition, an effort should be made to base vocabulary teaching on a systematic approach. Indeed, vocabulary introduction should rely on an ordered, cumulative and associative construction of lexical knowledge. This suggestion implies an organization of vocabulary introduction where $\mathrm{V}$ - that is, the new vocabulary which has been introduced and acquired - is followed by $\mathrm{V}+1$, then by $(\mathrm{V}+1)+1,((\mathrm{~V}+1)+1)+1$, and so on. In this sense, vocabulary introduction is developed upon a continuous line (see figure 3 ).

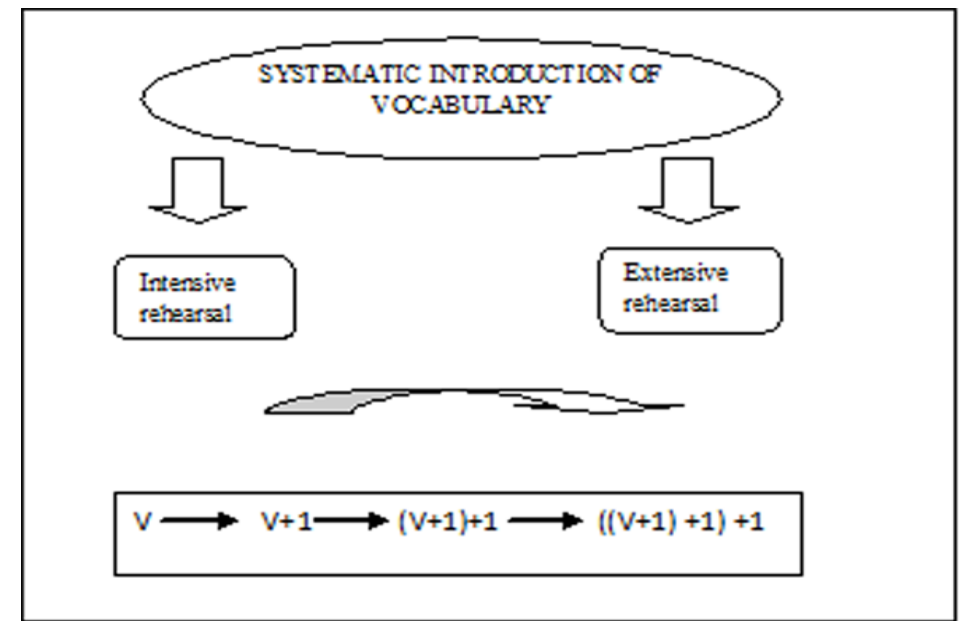

Figure 3. Systematic introduction of vocabulary

Nonetheless, it is important to remark that not only should vocabulary introduction be continuous and cumulative, but it should look that way, too. Students should feel that they have the opportunity to use what they have learned. This feeling can be fostered by a programme such as the one suggested here. Hence, the combinations of Vs and $1 \mathrm{~s}$ 
should not be understood as separate entities but as part of a cogent whole which is gradually established and reflected in the students' vocabulary knowledge.

An organized presentation of vocabulary might contribute towards an organized knowledge, which is considered to be better for learning, retaining and accessing. Therefore, it is necessary to determine how much and which vocabulary should be contained in coursebooks or introduced during a whole school year. Only in this way can the programme be successful. The programme should be built upon both intensive and extensive rehearsal. The former refers to the number of times a word occurs in one didactic unit. The programme should promote the treatment of all target words with the same intensity. This means that all target words should receive the same degree of attention in the textbook. The latter involves periodical recycling. That is to say, not only should target vocabulary be worked intensively for a short period of time, but it should also be revisited at certain points of the learning process.

For the idea to be successful, several members of the teaching-learning community have to be involved. In the first place, the teacher trainer is essential here. S/he should encourage teachers to adopt a critical view towards class materials. Trainers should instruct teachers about the identification and improvement of lessons, didactic units and textbooks which are considered lexically poor. Thus, trainers should join efforts and promote seminars specifically devoted to the selection and adaptation of didactic materials. In this sense, they could help teachers overcome possible insecurities when forming their opinions about a textbook. In these courses, teachers should learn how to analyze the quality of a textbook from the perspective of vocabulary as well as how to improve its lexical content.

In the second place, there is no doubt that the most direct link between the vocabulary input found in the textbook and the student is the teacher. S/he is usually responsible for selecting the EFL textbook which is to be used in class. For this reason, teachers should take a critical approach towards the overwhelming range of didactic materials on offer. Moreover, they should communicate the importance of vocabulary learning to their students. In fact, promotion and monitoring of a systematic approach to vocabulary learning is a possible way of doing this. Finally, the research community also has a role here. They should take the initiative in establishing links with teachers, resource designers and the rest of the teaching community, so that systematic vocabulary introduction can be possible.

The study shows that regular introduction favours acquisition. Yet, we are still far from knowing the optimum number of words and the rate at which they should be introduced. We are at the beginning of the path. All we have are suggestions and intuitions. In order to know these intuitions are on the right path we need to check whether students' abilities are in line with them. That is to say, we need to keep on investigating in order to know whether the suggested rate of introduction corresponds to the learners' rate of acquisition.

\section{Concluding remarks}

The present study shows that there is a significant relationship between Gries' index and L2 vocabulary acquisition. That is to say, those words more regularly distributed 
seem to be better acquired. This fact implies that the regular introduction of vocabulary may have a positive effect for learners. Studies like this one highlight the importance of systematic introduction in L2 vocabulary teaching. Therefore, a systematic approach to vocabulary learning should be based on intensive and extensive rehearsal. All the members of the teaching community should be aware of that, and transmit this approach to students.

\section{REFERENCES}

Alcaraz-Mármol, G. (in press). "Vocabulary input in classroom materials:Two EFL coursebooks used in Spanish schools", in Revista Española de Lingüistica Aplicada.

Brown, C. (1993). "Factors affecting the acquisition of vocabulary" in T. Huckin, M. Haynes and J. Coady (eds.), Second Language Reading and Vocabulary. Ablex, Norwood: N.J., 63-286.

Gries, S. (2008). "Dispersions and adjusted frequencies in corpora", in International Journal of Corpus Linguistics, 13, 4: 403-37.

Horst, M., Cobb, T., and Meara, P. (1998). "Beyond a Clockwork Orange: acquiring second language vocabulary through reading", in Reading in a Foreign Language, 11, 2: 207-23.

Hulstijn, J., Hollander, M. and Greidanus, T. (1996). "Incidental vocabulary learning by advanced foreign language students: the influence of marginal glosses, dictionary use, and reoccurrence of unknown words", in The Modern Language Journal, 80, 3: 327-39.

Jiménez Catalán, R. M. and Moreno Espinosa, S. (2005). "Using Lex30 to measure the L2 productive vocabulary of Spanish primary learners of EFL", in Vial, 13, 2: 27-44.

Jiménez Catalán, R. M. and Terrazas, M. (2008). "The Receptive Vocabulary of English Foreign Language Young Learners", in IJES, 2, 2: 201-15.

Kachroo, J.N. (1962). "Report on an investigation into the teaching of vocabulary in the first year of English", in Bulletin of the Central Institute of English, 33, 2: 67-72.

Laufer, B. (2005). "Lexical Frequency profiles: From Monte Carlo to the Real World. A response to Meara", in Applied Linguistics, 26, 4: 582-88.

Leech, G. N., Rayson, P. and Wilson, A. (2001). Word frequencies in written and spoken English: based on the British National Corpus. London: Longman.

Lyne, A. (1985). "Dispersion", in A. Lyne (ed.), The Vocabulary of French Business Correspondence: Word Frequencies, Collocations and the Problems of Lexicometric Method. Geneva, Paris: Slatkine-Champion, 101-24.

Meara, P. (1992). "Network structures and vocabulary acquisition in a foreign language", in P.J.L. Arnaud and H. Bejoint (eds.), Vocabulary and Applied Linguistics. London: McMillan, 6270.

Milton, J. (2009). Measuring Second Language Vocabulary Acquisition. Bristol: Multilingual Matters.

Nagy, W.E. and Herman, P.A. (1987). "Breadth and depth of vocabulary knowledge: implications for acquisition and instruction", in G. McKeown and M.E. Curtis (eds.), The Nature of Vocabulary Acquisition. New Jersay: LEA, 19-35.

Nation, I.S.P. (2001). Learning Vocabulary in Another Language. Cambridge: Cambridge University Press.

Orosz, A. (2009). “The growth of young learners' English vocabulary size”, in M. Nikilov (ed.), Early Learning of Modern Foreign Languages. Bristol: Multilingual Matters, 181-94.

Papiol, E. and Toth, M. (1999). Bugs 3 Pupil's Book. London: Macmillan Publishers. 
Pigada, M. and Schmitt, N. (2006). "Vocabulary acquisition from extensive reading: A case study", in Reading in a Foreign Language, 18, 1: 1-28.

Quinn, G. (1968). The English vocabulary of some Indonesian University entrants. English Department Monograph IKIP Kristen Satya Watjana: Salatiga. Reyes, M. J. (1999). "Incidencia de la variable 'curso' en el aprendizaje léxico", in Actas del XI Congreso Internacional de la Asociación de Lingüistica y Filología de la América Latina. ULPGC, Las Palmas de Gran Canaria, 1675-81.

Rott, S. (1999). "The effect of exposure frequency on intermediate language learners' incidental vocabulary acquisition and retention through reading", in Studies in Second Language Acquisition, 21, 4: 589-619.

Saragi, T., Nation, P., Meister, G.F. (1978). "Vocabulary learning and reading", in System, 3, 2: 7278.

Schmitt, N. (2000). Vocabulary in Language Teaching. Cambridge: Cambridge University Press.

Scholfield, P. (1991). "Vocabulary rate in coursebooks - living with an unstable lexical economy", in Proceedings of 5th Symposium on the description and/or comparison of English and Greek. Aristotle University, 11-32.

Waring, R. and Takaki, M. (2003). "At what rate do learners learn and retain new vocabulary from reading a graded reader?", in Reading in a Foreign Language, 15, 2: 130-163.

Webb, S. (2007). "Learning word pairs and glossed sentences: the effects of a single context on vocabulary knowledge", in Language Teaching Research, 11, 1: 63-81.

Yuen, K. (1997). Review of Allwright's (1981) paper 'Why use textbooks?' BEd assignment. University of Nottingham.

Zhang, H., Huang, C. and Yu, S. (2004). "Distributional consistency: as a general method for defining a core lexicon". Paper presented at Language Resources and Evaluation 2004, Lisbon, Portugal. 